$11-1-2015$

\title{
Statistical Modeling of Migration Attractiveness of the EU Member States
}

Tatiana Tikhomirova

Plekhanov Russian University of Economics

Yulia Lebedeva

Plekhanov Russian University of Economics, live_wire@mail.ru

Follow this and additional works at: http://digitalcommons.wayne.edu/jmasm

Part of the Applied Statistics Commons, Social and Behavioral Sciences Commons, and the Statistical Theory Commons

\section{Recommended Citation}

Tikhomirova, Tatiana and Lebedeva, Yulia (2015) "Statistical Modeling of Migration Attractiveness of the EU Member States," Journal of Modern Applied Statistical Methods: Vol. 14 : Iss. 2 , Article 19.

DOI: $10.22237 /$ jmasm/1446351480

Available at: http://digitalcommons.wayne.edu/jmasm/vol14/iss2/19

This Regular Article is brought to you for free and open access by the Open Access Journals at DigitalCommons@WayneState. It has been accepted for inclusion in Journal of Modern Applied Statistical Methods by an authorized editor of DigitalCommons@WayneState. 


\section{Statistical Modeling of Migration Attractiveness of the EU Member States}

\section{Cover Page Footnote}

1. Eurostat, Population and social conditions, Author: Fabio SARTORI, 45/12 2. Migrants in Europe A statistical portrait of the first and second generation, Luxembourg: Publications Office of the European Union, 2011, Printed in Belgium 3. Official site - Eurostat/ electronic resource.

http://epp.eurostat.ec.europa.eu/statistics_explained/index.php/

Migration_and_migrant_population_statistics 4. The official website of the National Institute of Statistics

(Romania) http://www.insse.ro 5. The official site of the National Statistics Office (Malta) / Electronic resource http://www.nso.gov.mt 6. Tikhomirov N.P., Tikhomirova T.M., Oushmaev O.S. Econometric methods and multivariate statistical analysis: A Textbook. - Moscow: Economics, 2011. - 647 pages 7.

Electronic bulletin which is published with the support of the French National Institute of Demographic Studies (INED) in collaboration with the Institute of Demography at the National Research University "Higher School of Economics' / Electronic resource. http://demoscope.ru/weekly/2013/0553/index.php 


\section{Statistical Modeling of Migration Attractiveness of the EU Member States}

\section{Tatiana Tikhomirova}

Plekhanov Russian University of Economics Москва, Russia

\author{
Yulia Lebedeva \\ Plekhanov Russian University of Economics \\ Москва, Russia
}

Identifying the relationship between the migration attractiveness of the European Union countries and their level of socio-economic development is investigated. An approach is proposed identify influences on migration socio-economic characteristics, by aggregating and reducing their diversity, and substantiating the cause-and-effect relationships of the studied phenomenon. A stable classification of countries scheme is developed according to the attractiveness of migration on aggregate factors, and then an econometric model of a binary choice using panel data for 2008-2010 was applying, quantifying the impact of aggregate designed factors on immigration and emigration.

Keywords: Immigration attractiveness, immigration, emigration, applied statistics, multivariate statistical techniques, multi-dimensional space, the panel data.

\section{Introduction}

Migration is "one of the most important challenges of the $21^{\text {st }}$ century" (Albertinelli et al., 2011; "Migrants in Europe", 2012). This phenomenon, caused by rising unemployment, increasing crime, the destruction of the traditional indigenous way of life, increasing the burden on the budget, and many other negative consequences, particularly when unregulated or illegal urges governments of developed countries to take certain measures to regulate migration flows within the appropriate migration policies.

The problems of developing an effective migration policy are also becoming more pressing in the European Union (EU), particularly because of the open borders within the framework of this community. In such a situation, the regulation of migration within the EU is usually associated with exposure to the factors generating the process and the living conditions of the population, of which, according to experts, the most important is the difference in the levels of living of the population and socio-economic development of the community.

\section{Prof. Dr. Tikhomirova is Professor of Economics. Email Tatiana Tikhomirova at} t_tikhomirova@mail.ru.Email Yulia Lebedevaat live_wire@mail.ru. 


\section{TIKHOMIROVA \& LEBEDEVA}

An important stage of the development and validation of measures of migration policy in the EU is the clusterization of countries within homogeneous groups in terms of socio-economic development and identification of the main reasons - factors that determine the patterns of intra-group and between group processes. In this regard, the construction of a sustainable clusterization of EU countries in terms of the attractiveness of migration is considered, as well as the identification of factors that have an impact on migration, and cause the differences in the development of EU countries, is relevant.

In this study, the 29 countries of the European Union: Austria, England, Belgium, Bulgaria, Hungary, Germany, Denmark, Greece, Ireland, Spain, Italy, Cyprus, Latvia, Lithuania, Luxembourg, Malta, Netherlands, Norway, Poland, Portugal, Romania, Slovakia, Slovenia, Finland, France, Croatia, Czech Republic, Sweden, Estonia were examined for the period of 2008 to 2010, on 84 social, economic and political indicators: compensation of employees, GDP per capita in PPS, life expectancy at birth by sex, the number of pupils and students, self-reported unmet need for medical examination or treatment by income quintile, etc. (Sartori, 2012; "Migration and migrant population statistics", 2015; Institul National de Statistica, n.d.; National Statistics Office, Malta, n.d.). All these characteristics are given in comparable units of measurement.

In general, the source data set is a parallelepiped (see Figure 1), where the axis $P_{i}$ belongs to EU member states $i=\overline{1.29}$, the axis $X_{j}$ belongs the previously mentioned socio-economic and demographic characteristics of EU countries $j=\overline{1.84}$, and the axis $t_{k}$ is time interval, $t=\overline{1.3}$.

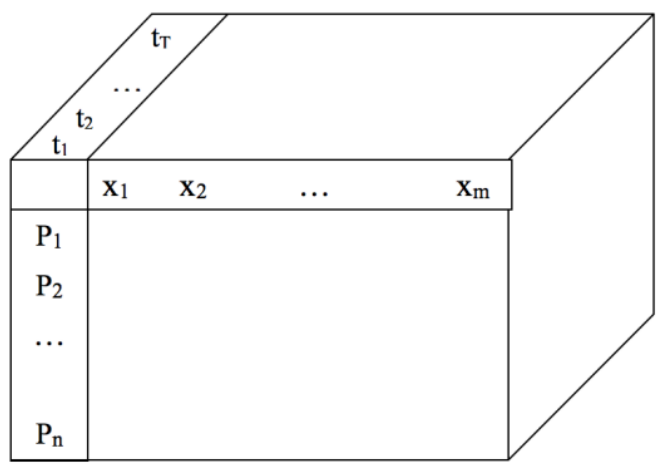

Figure 1. Parallelepiped of initial data on indicators of the attractiveness of the EU member states migration 


\section{STATISTICAL MODELING OF MIGRATION ATTRACTIVENESS}

When considering the information set numerous problems appear: 1) selecting the informative features that have a significant statistical effect on the migration, 2) reducing the dimensions of the array of information and the transition to the matrix representation of the data, 3) selecting the correct mathematical tools for analyzing small samples in which the number of signs exceeds the number of objects $(29 \times 84)$, making it impossible to construct the set econometric models, 4) recovering the gaps in the baseline data, 5) leveling the effect of multicollinearity between variables without significant loss of information content of the feature space (Tikhomirov, Tikhomirova, Oushmaev, 2011).

The first problem (the assessment of the relationship between factors and migration attractiveness of countries) was solved in several stages. With the help of multiple correlation analysis those features that have the greatest impact on statistical indicators of officially registered immigrants and emigrants were selected from the total number of socio-economic and demographic indicators. It was found that 32 of the 84 characteristic have a significant impact on immigration and 9 characteristic have a significant impact on emigration.

In the next step the combined influence of selected characteristics on migration attractiveness of countries was investigated, using the approach proposed by the authors: scaling of countries by aggregated, randomized indicators. This approach lies in the fact that the selected indicators are assigned levels according to the following principle: if the data has a direct correlation to the corresponding endogenous variable, the number of officially registered emigrants, or the number of registered immigrants, i.e., the correlation coefficient between the factor variable and efficient variable is significant and positive, then the ranks assigned to each variable are as follows: the observation with the highest value is assigned the maximum rank and levels are in descending order.

If the variable has an inverse relationship with the endogenous variable, i.e. the correlation coefficient is significant and negative, then the ranks are assigned to each variable in the reverse order: the observation with the largest value has a rank corresponding to one and then ranks are arranged in ascending order. Then the sum of the ranks corresponding to all variables influencing the emigration and immigration for each country is calculated:

$$
R_{i}=\sum_{j} R_{i j}
$$




\section{TIKHOMIROVA \& LEBEDEVA}

where $i$ is the serial number of the country $i=\overline{1.29} ; j$ is the serial number of variable $X_{j}, j=\overline{1.9}$ (for emigration) and $j=\overline{1.32}$ (for immigration), $R_{i}$ is the sum of the ranks in the country with the number of $i, R_{i j}$ is the rank assigned to the $i^{\text {th }}$ observation of the $j^{\text {th }}$ variable.

In the next step, the percentage deviation of the sum of the rank of each country from the median level of emigration and immigration in the EU respectively is calculated:

$$
\Pi_{i}=\frac{\left(R_{i}-M\right)}{M} * 100 \%
$$

where $M$ is the median for all $R_{i}$.

The scaling was produced with respect to values of percentage: from the largest percentage to the lowest value of percentage. The results of the calculations by the variables of the attractiveness of emigration are presented in Figure 2. Figure 3 shows the ranking of EU countries, which was built for the number of officially registered emigrants per thousand inhabitants.

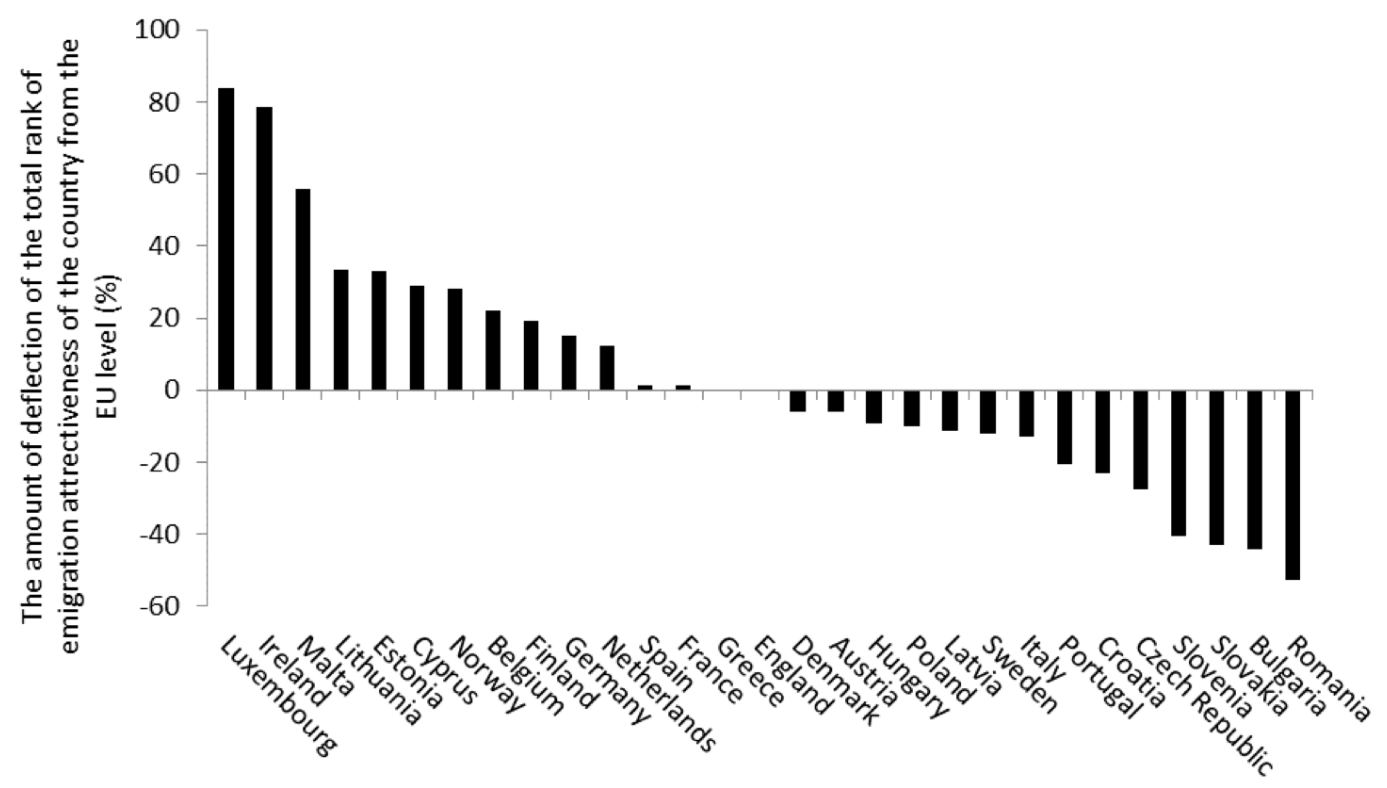

Figure 2. Distribution of the EU countries with respect of emigration attractiveness 


\section{STATISTICAL MODELING OF MIGRATION ATTRACTIVENESS}

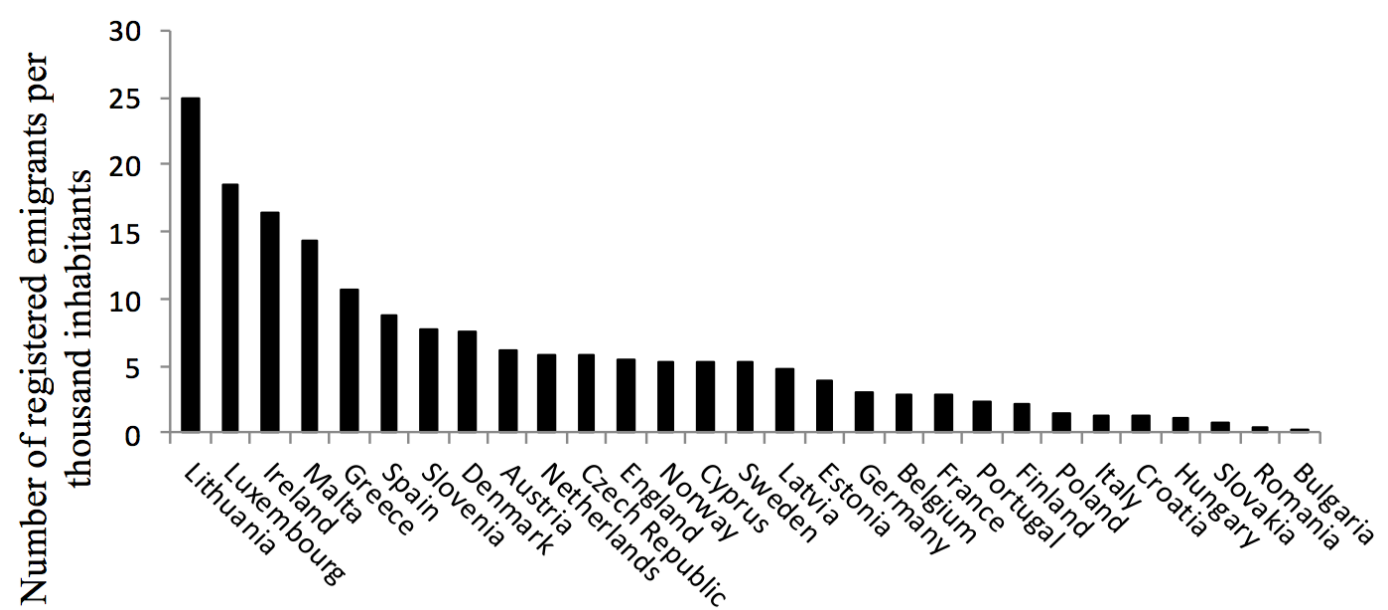

Figure 3. The distribution of EU countries by number of registered emigrants per thousand inhabitants

Comparing the histograms placed in Figure 2 and Figure 3 indicates that these extreme values are the same. This indicates that the selected explanatory variables are really informative and their joint effect on the attractiveness of emigration is significant. Moreover, in Figure 2 and Figure 3, heterogeneity of the EU countries by selected characteristics is observed (their scatter relative to the EU median level is greater than $70 \%$ ), which leads to the need for clustering of countries by studied characteristics. Similar results were obtained during the distribution of countries by number of immigrants and the characteristics that affect the level of immigration.

The next problem which we solved in this paper was caused by multicollinearity selected features. Statistics of Pearson has confirmed the presence of multicollinearity in features of emigration attractiveness $\left(\chi_{\text {est }}^{2}=60.8 \succ \chi_{\text {tab. }}^{2}=50.9\right)$ on $99 \%$ confidence level. It should be noted that the multicollinearity of the features of immigration attractiveness was not statistically established.

Cluster analysis (see Figure 4), which was built for the 9 variables of emigration attractiveness, also shows a relationship between them. 


\section{TIKHOMIROVA \& LEBEDEVA}

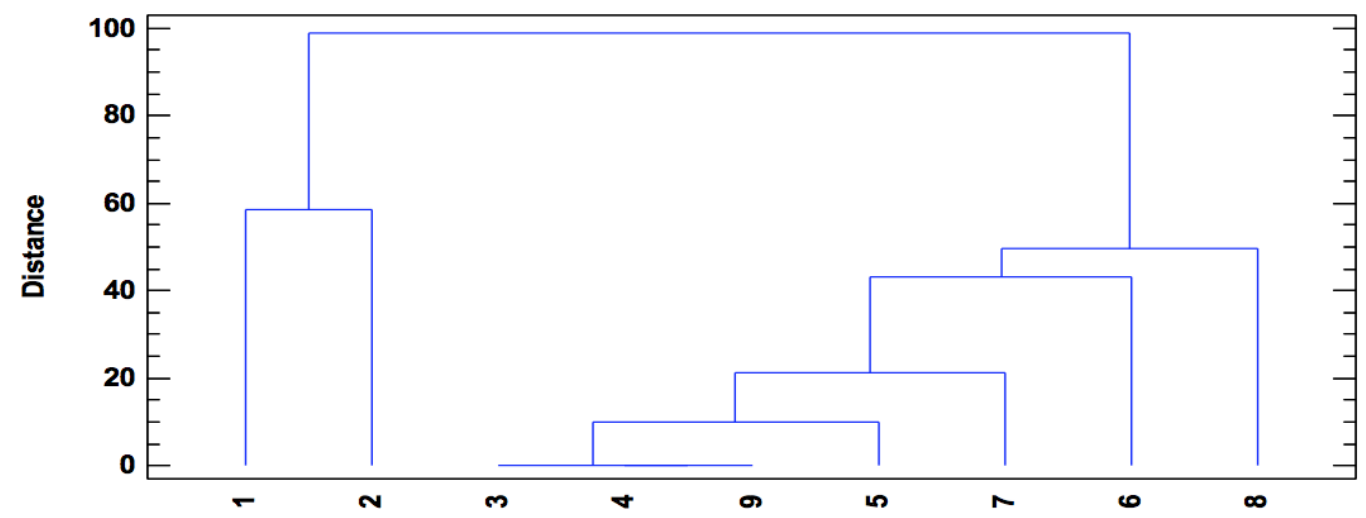

Figure 4. Cluster analysis dendrogram constructed for the 9 variables of emigration attractiveness using method farthest neighbor (the square of the Euclidean metric)

The dendrogram (Figure 4) shows that the variables numbered 3, 4, 9 are collinear. Step by step, we removed one variable, which had the least variation, from consideration. This meant that the space variables of emigration attractiveness of EU countries were reduced with no loss of informativity and the problem of multicollinearity was solved. Statistics of Pearson after the removal of collinear variables (no. 4 and 9) was: $\left(\chi_{\text {est. }}^{2}=32.8 \prec \chi_{\text {tab. }}^{2}=38.9\right)$ for $\alpha=0.01$.

A similar approach was applied to reduce the feature space on the immigration attractiveness of EU countries.

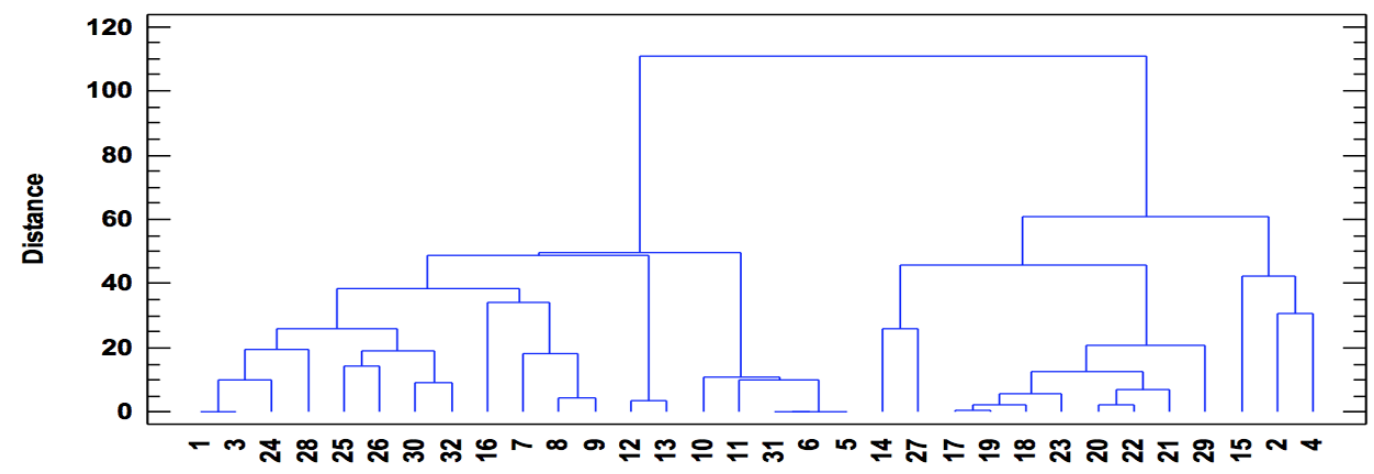

Figure 5. The dendrogram of the cluster analysis for the 32 features of immigration attractiveness of the EU (the square of the Euclidean metric) 


\section{STATISTICAL MODELING OF MIGRATION ATTRACTIVENESS}

As follows from the dendrogram (Figure 5), many of the characteristics are closely related, although the statistic of Pearson did not confirm the presence of multicollinearity for them, apparently, due to the excessive multi-dimensionality (the number of variables, in this case exceeds the number of observations). For example, variables number 1 and 3 , as well as 5 and 6 , are collinear so for further research it is advisable to leave only one of each pair, based on the principle that the most preferred variable is the one with higher variability.

Reduction of the feature space of immigration attractiveness was conducted in several iterations. Moreover, in each iteration of the classification we built on a selected set of variables until the requirements of sustainability were met (Tikhomirov et al. 2011). In order to obtain a stable classification 9 iterations took place. The final dendrogram of cluster analysis of EU countries by immigration attractiveness based on many of its defining characteristics is represented in Figure 6.

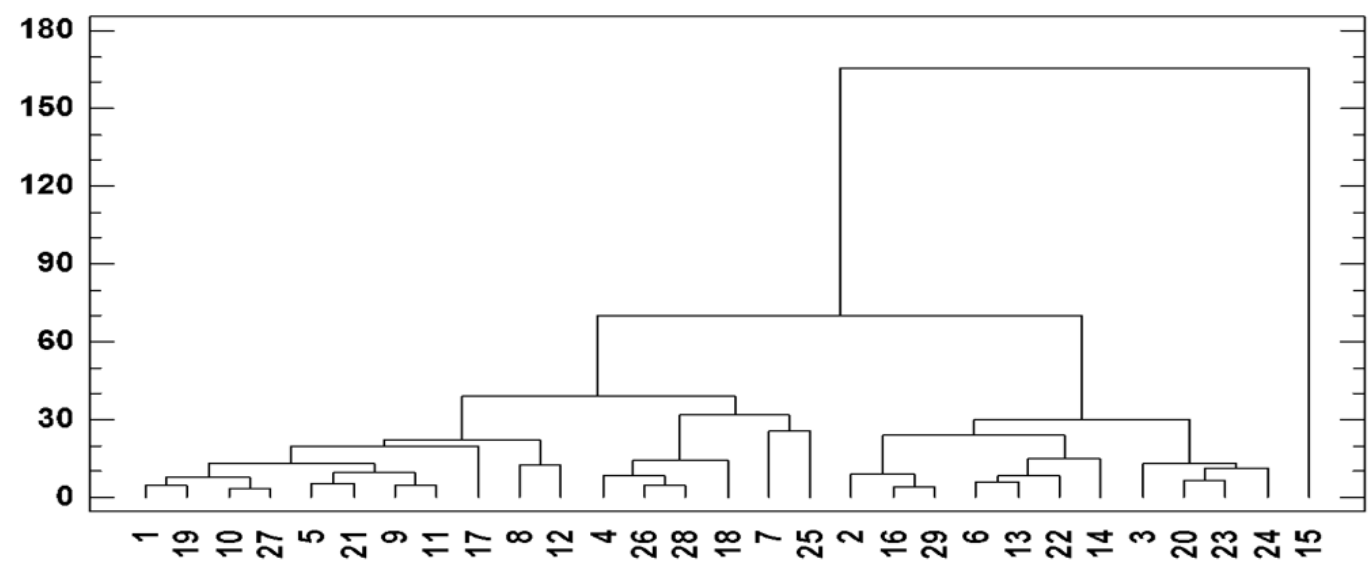

Figure 6. The dendrogram of cluster analysis of immigration attractiveness of the EU countries by using far neighbor method (the square of the Euclidean metric)

From the obtained clustering of countries it follows that they can be divided into two groups of immigration attractiveness (see Table 1 and Figure 7). The first group includes countries of the former capitalist camp, and the second group has the countries of the former socialist camp. Luxembourg (the object no.15) is located out of the general mass of EU countries and cannot be added to either of the groups. 


\section{TIKHOMIROVA \& LEBEDEVA}

Table 1. The distribution of EU countries by immigration attractiveness by homogeneous groups

\begin{tabular}{cl}
\multirow{2}{*}{1 group } & Belgium, Denmark, Germany, Ireland, Greece, Spain, \\
& France, Italy, Cyprus, Malta, the Netherlands, Austria, \\
& Portugal, Finland, Sweden, England, Norway. \\
\hline \multirow{3}{*}{2 group } & Bulgaria, The Czech Republic, Estonia, Latvia, \\
& Lithuania, Hungary, Poland, Romania, Slovenia, \\
& Slovakia, Croatia.
\end{tabular}

On the map (Figure 7) these three groups are displayed. The blue color indicates the countries included in the first group, and the red indicates those in the second. Countries which are not included in the review are white.

The quality of the classification was confirmed by discriminant analysis. The percentage of correctly classified cases (in the application of discriminant analysis) was $100 \%$. From the results of the discriminant analysis, shown in Figure 8, it follows that the groups of countries are located far enough away from each other to indicate their significant differences in immigration attractiveness.

As a result of the statistical analysis 15 variables which have an impact on immigration were selected from 84 variables, such as: final consumption expenditure of households and non-profit organizations serving households as a percentage of GDP, net national income as a percentage of GDP, direct investment flows abroad as a percentage of GDP, natural decline in population per thousand residents, the number of students in higher education per one thousand inhabitants (the number of graduates between the ages of 20-29 years in mathematics, science and technology per thousand population), employment rate by highest level of education attained (the percentage of age group 20-64 years), overcrowding rate by tenure status (the percentage of owner, with mortgage or loan), the percentage of individuals aged 16 to 74 using the Internet for ordering goods or services from other EU countries, the percentage of individuals in aged 16 to 74 using a mobile phone via UMTS $(3 \mathrm{G})$ to access the Internet, number of deaths due to accidents, selected from standardized death rate by 100000 inhabitants, individuals seeking information on the Internet with the purpose of learning, life expectancy at birth (healthy life years) and 7 variables which have an impact on emigration: the gross fixed capital formation, defined as investment's percentage of GDP; the gross fixed capital formation, defined as investment's percentage of GDP; population of foreigners by citizenship; the 


\section{TIKHOMIROVA \& LEBEDEVA}

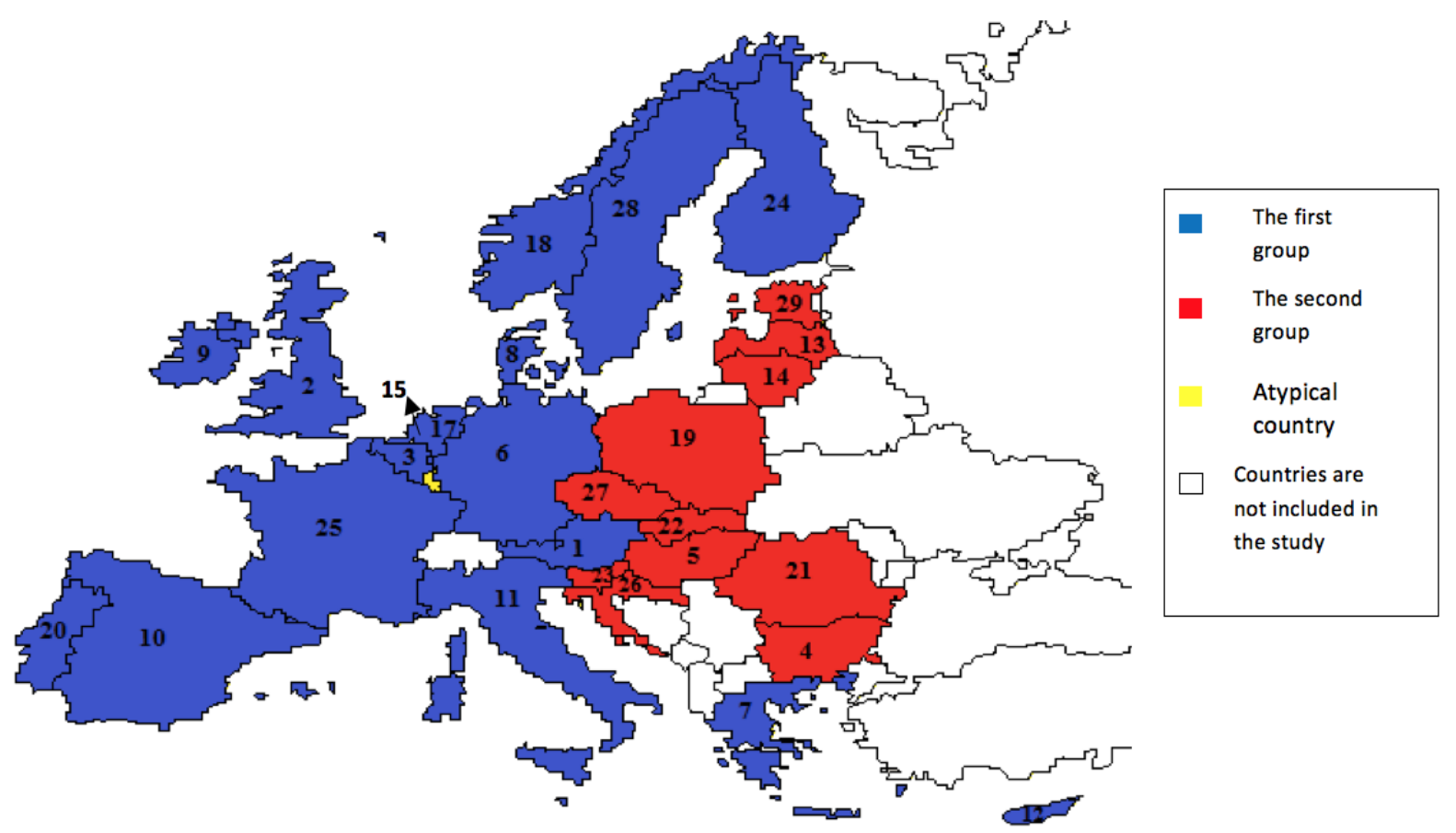
1 Austria
6 Germany
11 Italy
16 Malta
21 Romania
26 Croatia
2 England
7 Greece
12 Cyprus
17 Netherlands
22 Slovakia
27 Czech Republic
3 Belgium
8 Denmark
13 Latvia
18 Norway
23 Slovenia
28 Sweden
9 Ireland
14 Lithuania
19 Poland
24 Finland
29 Estonia

Figure 7. The dendrogram of cluster analysis of immigration attractiveness of the EU countries by using far neighbor method (the square of the Euclidean metric) 


\section{STATISTICAL MODELING OF MIGRATION ATTRACTIVENESS}

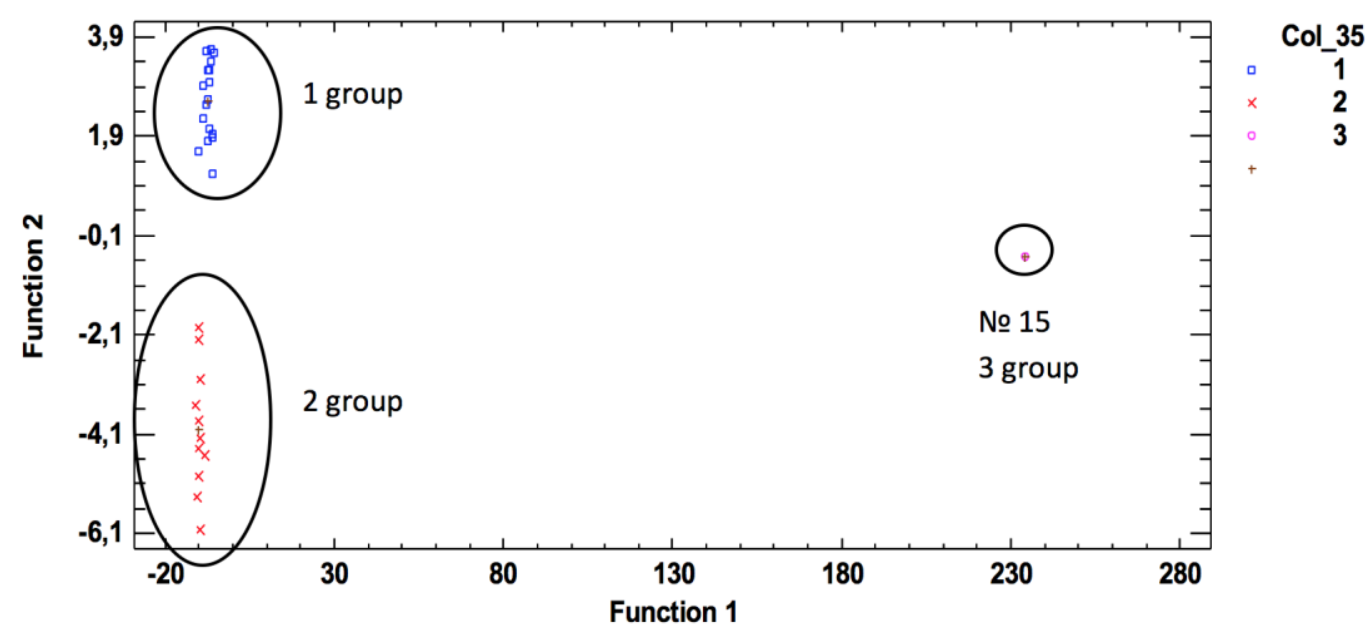

Figure 8. The distribution of EU countries by immigration attractiveness in projections of the discriminant functions

gender differences in the risk of poverty, the percentage from the group 65 years or over; the percentage of individuals aged 16 to 74 using the Internet for ordering goods or services from other EU countries; the volume of passenger transport relative to GDP.

In order to construct models of immigration and emigration attractiveness in the EU countries, the method of principal components was applied to selected variables. At this stage, aggregate variables were built. They affect the attractiveness of immigration and emigration, and are used in econometric modeling as regressors.

It should be noted that the classification of EU countries, held on principal components, retained their membership in the group (Figure 10). 


\section{STATISTICAL MODELING OF MIGRATION ATTRACTIVENESS}

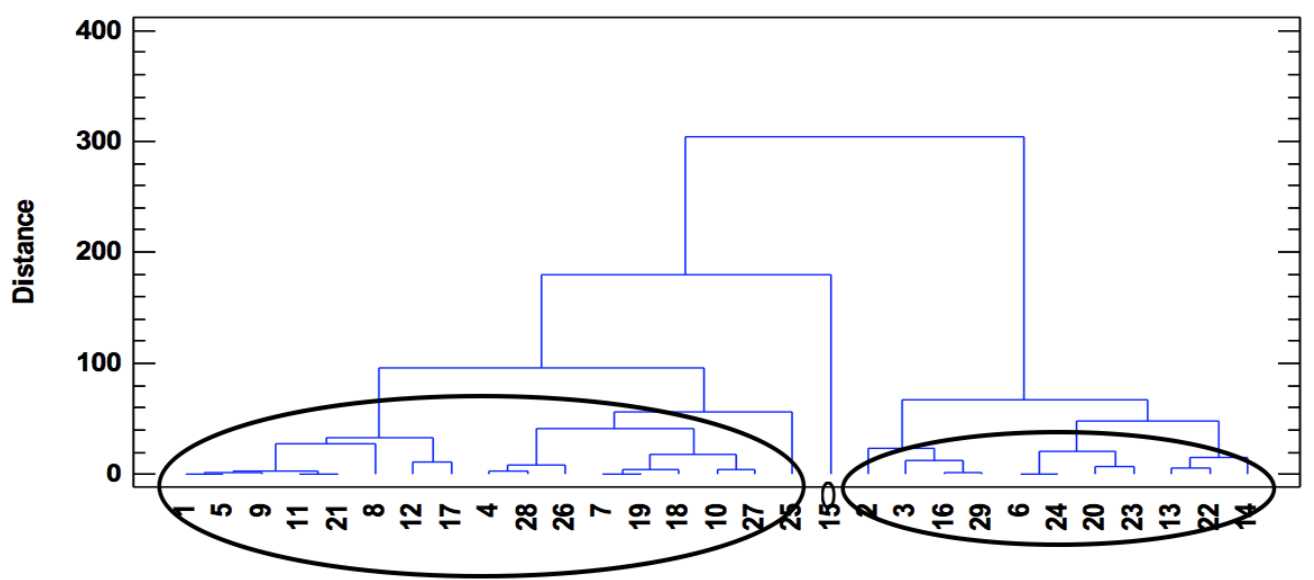

Figure 9. The dendrogram of the cluster analysis of the EU immigration appeal, based on principal components

This classification of countries is stable, which is confirmed by the results of the discriminant analysis (Figure 10).

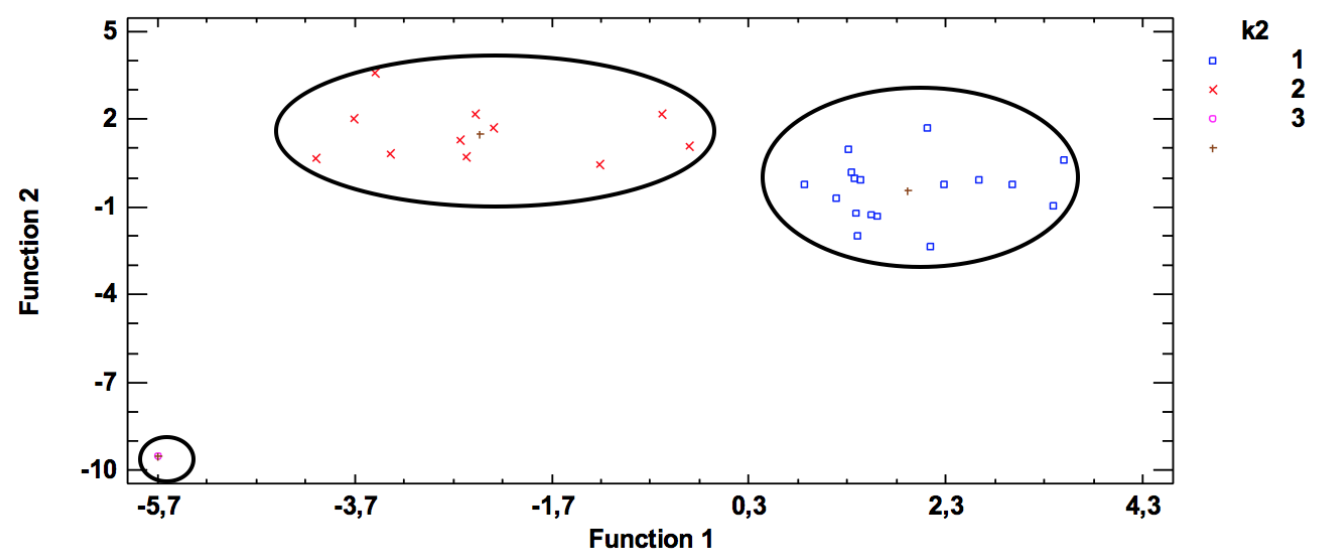

Figure 10. The distribution of the EU countries by main components of immigration attractiveness in projections of the discriminant functions 


\section{TIKHOMIROVA \& LEBEDEVA}

Similar calculations were carried out by emigration in EU countries. Classification of the EU countries of emigration attractiveness is robust and is presented in Figure 11 and Table 2.

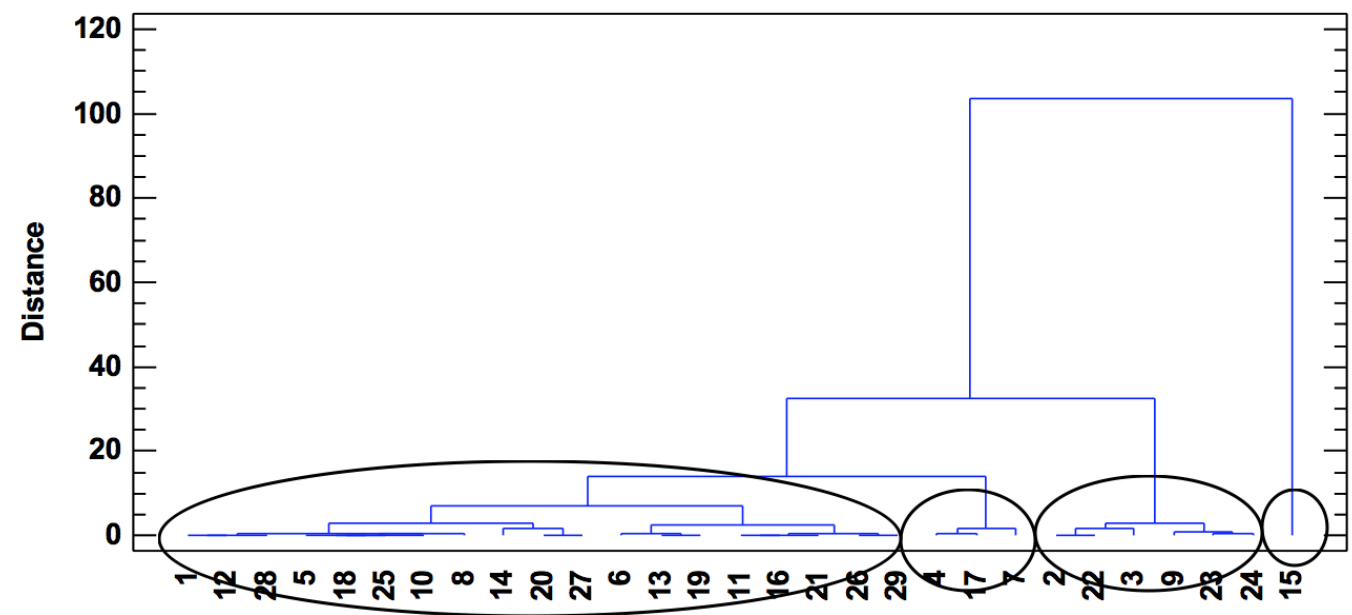

Figure 11. The distribution of the EU countries by main components of immigration attractiveness in projections of the discriminant functions

Table 2. Distribution of the EU countries by emigration attractiveness by homogeneous groups

Austria, England, Belgium, Hungary, Germany, Greece,

1 group France, Italy, Cyprus, Latvia, Lithuania, Netherlands, Norway, Poland, Portugal, Finland, Croatia, Sweden, Estonia.

\begin{tabular}{ll}
\hline 2 group & Denmark, Ireland, Malta. \\
\hline 3 group & Bulgaria, Spain, Romania, Slovakia, Slovenia, Czech \\
& Republic
\end{tabular}

Unclassified country Luxembourg.

Consider the results of principal component analysis for the characteristics of the immigration and emigration attractiveness of EU countries. The system of equations of principal components of immigration is as follows: 


\section{STATISTICAL MODELING OF MIGRATION ATTRACTIVENESS}

$$
\left\{\begin{aligned}
F_{1}= & -0.22 x_{2}+0.14 x_{4}-0.25 x_{5}-0.3 x_{7}-0.1 x_{14}+0.03 x_{15}-0.28 x_{16}-0.36 x_{18} \\
& +0.3 x_{24}-0.30 x_{25}-0.3 x_{26}-0.25 x_{27}+0.24 x_{28}+0.35 x_{33}+0.22 x_{34} \\
F_{2}= & 0.27 x_{2}-0.09 x_{4}-0.12 x_{5}-0.02 x_{7}-0.46 x_{14}-0.39 x_{15}+0.19 x_{16}-0.07 x_{18} \\
& -0.06 x_{24}-0.19 x_{25}-0.29 x_{26}-0.39 x_{27}-0.32 x_{28}+0.19 x_{33}+0.28 x_{34} \\
F_{3}= & 0.34 x_{2}+0.62 x_{4}-0.42 x_{5}-0.27 x_{7}+0.15 x_{14}-0.04 x_{15}+0.34 x_{16}-0.01 x_{18} \\
& +0.01 x_{24}+0.16 x_{25}-0.08 x_{26}+0.04 x_{27}+0.25 x_{28}+0.07 x_{33}-0.04 x_{24} \\
F_{4}= & 0.47 x_{2}-0.03 x_{4}+0.13 x_{5}+0.39 x_{7}+0.32 x_{14}+0.49 x_{15}+0.00 x_{16}+0.17 x_{18} \\
& -0.15 x_{24}-0.26 x_{25}-0.28 x_{26}+0.00 x_{27}+0.01 x_{28}+0.22 x_{33}+0.16 x_{24}
\end{aligned}\right.
$$

In the component $F_{1}$ the following variables have the greatest weight: 7 (the natural population change per 1000 inhabitants), 18 (the overcrowding rate by tenure status), 24 (the percentage of individuals aged 16 to 74 using the Internet for ordering goods or services from other EU countries), 25 (the percentage of individuals in aged 16 to 74 using a mobile phone via UMTS (3G) to access the Internet), and 26 (the percentage of the inhabitance from age 16 to 74 who use a laptop with wireless connection to access the Internet). Moreover, all variables except 18 have positive weights. It was decided that the $F_{1}$ describes the technical equipment of the country.

In the component $F_{2}$ the following variables have the greatest weight: 14 (the students in the tertiary education system per 1000 inhabitants), 15(science and technology graduates, defined as tertiary graduates in science and technology per 1000 of population aged 20-29 years and graduates in mathematics, science and technology per 1000 of population aged 20-29), 27 ( number of deaths due to accidents, selected from standardized death rate by 100000 inhabitants), and 28 (individuals seeking information on the Internet with the purpose of learning, from individuals aged 16 to 74, who used the Internet within the last three months before the survey). All variables included in the component have negative weights. In this situation, it was assumed that $F_{2}$ is responsible for the low level of skills of the economically active population.

In the component $F_{3}$ the following variables have the greatest weight: 2 (the final consumption expenditure of households and non-profit institutions serving households measured as percentage of GDP), 4 (the net national income), 16 (the employment rate by highest level of education attained, from the age group 20-64 years. All variables included in this component have positive weights, so we considered it appropriate to characterize the $F_{3}$ as the level of production. 


\section{TIKHOMIROVA \& LEBEDEVA}

In the component $F_{4}$ the following variables have the greatest weight: 2 (the final consumption expenditure of households and non-profit institutions serving households as a percentage of GDP), 7 (the natural population change per 1000 inhabitants), 14 (the students in the tertiary education system per 1000 inhabitants), and 15 (science and technology graduates, defined as tertiary graduates in science and technology per 1000 of population aged 20-29 years and graduates in mathematics, science and technology per 1000 of population aged 20-29). $F_{4}$ can be interpreted as a country with a production oriented economy.

Principal component analysis applied to the variables of emigration attractiveness identified the following factors:

$$
\left\{\begin{array}{l}
F_{1}=0.55 x_{1}-0.16 x_{2}-0.39 x_{3}-0.26 x_{5}-0.43 x_{6}-0.42 x_{7}-0.31 x_{8} \\
F_{2}=0.15 x_{1}+0.76 x_{2}-0.19 x_{3}+0.04 x_{5}-0.39 x_{6}+0.15 x_{7}+0.43 x_{8} \\
F_{3}=0.16 x_{1}+0.10 x_{2}+0.24 x_{3}+0.70 x_{5}-0.30 x_{6}+0.22 x_{7}-0.53 x_{8}
\end{array}\right.
$$

In the component $F_{1}$ the following variables have the greatest weight: 1 (the gross fixed capital formation, defined as investment's percentage of GDP), 6 (the gender differences in the risk of poverty, the percentage from the group 65 years or over), 7 (percentage of individuals aged 16 to 74 using the Internet for ordering goods or services from other EU countries). The first variable has a positive weight, and the other two have negative. This suggests that $F_{1}$ is responsible for the underdevelopment of the domestic market of a country.

In the component $F_{2}$ the following variables have the greatest weight: 2 (the net national income) and 8 (the volume of passenger transport relative to GDP). All variables included in this component have positive weights. In this regard, $F_{2}$ can be interpreted as the skill level of the economically active population in a country.

In the component $F_{3}$ the following variables have the greatest weight: 5 (population of foreigners by citizenship) and 8 (the volume of passenger transport relative to GDP). It was decided that the component $F_{3}$ is responsible for the shortage of labor in a country.

For the studied countries, binary choice econometric models were built by panel data using principal components, which allowed us to quantify the degree of influence of identified factors in the migration attractiveness of the EU countries. The logit model for immigration in the EU countries, which is based on principal components (see Equation 3) is presented in Table 3. 


\section{STATISTICAL MODELING OF MIGRATION ATTRACTIVENESS}

As can be seen from the results of Table 3 coefficients of regressors $F_{1}$ and $F_{2}$ are statistically different from zero. In our case, confidence intervals for the parameter estimates $\hat{\beta}_{1}$ and $\hat{\beta}_{2}$ do not cover the zero on $95 \%$ confidence level. Factors $F_{3}$ and $F_{4}$ are not statistically significant, so on the second iteration of the modeling process they were removed from consideration (see Table 4).

Table 3. Distribution of the EU countries by emigration attractiveness by homogeneous groups

$\begin{array}{lllr}\text { Logistic regression } & \text { Number of obs } & & 81 \\ & \text { LR chi2(4) } & = & 17.93 \\ \text { Log 1ikelihood }=-41.87143 & \text { Prob }>\text { chi2 } & = & 0.0013 \\ & \text { Pseudo R2 } & = & 0.1764\end{array}$

\begin{tabular}{r|rcccrr}
\hline $\mathrm{y}$ & Coef. & Std. Err. & $\mathrm{z}$ & $\mathrm{P}>|\mathrm{z}|$ & [95\% Conf. & Interval] \\
\hline F1 & .3368228 & .1345433 & 2.50 & 0.012 & .0731228 & .6005228 \\
F2 & -.673362 & .2194932 & -3.07 & 0.002 & -1.103561 & -.2431632 \\
F3 & -.2054553 & .2641865 & -0.78 & 0.437 & -.7232513 & .3123407 \\
F4 & -.4624412 & .3028866 & -1.53 & 0.127 & -1.056088 & 1312057 \\
_cons & .9061329 & .2862913 & 3.17 & 0.002 & .3450122 & 1.467254 \\
\hline
\end{tabular}

Table 4. Statistical characteristics of the quality of the logit model of immigration

$\begin{array}{lllr}\text { Logistic regression } & \text { Number of obs } & & 81 \\ & \text { LR chi2(2) } & = & 14.43 \\ \text { Log likelihood }=-43.623255 & \text { Prob > chi2 } & = & 0.0007 \\ & \text { Pseudo R2 } & = & 0.1419\end{array}$

\begin{tabular}{r|rcccrr}
\hline$y$ & Coef. & Std. Err. & $z$ & P $|z|$ & [95\% Conf. Interva1] \\
\hline F1 & .2942894 & .1244197 & 2.37 & 0.018 & .0504313 & .5381476 \\
F2 & -.606015 & .2068514 & -2.93 & 0.003 & -1.011436 & -.2005938 \\
_cons & .8880164 & .2751494 & 3.23 & 0.001 & .3487334 & 1.427299 \\
\hline
\end{tabular}

Logit model of immigration in EU countries has the form:

$$
P\left(y_{i}=1 \mid x_{i}\right)=\frac{e^{0.9+0.3 F_{1}-0.6 F_{2}}}{1+e^{0.9+0.3 F_{1}-0.6 F_{2}}} \operatorname{HP}\left(y_{i}=1 \mid x_{i}\right)=\frac{1}{1+e^{0.9+0.3 F_{1}-0.6 F_{2}}}
$$

Factors $F_{1}$ and $F_{2}$ have an impact on immigration in the EU countries. The first factor $F_{1}$ has a positive impact, but factor $F_{2}$ has a negative one. It can be reasonably argued that an increase in technical equipment (development of IT 


\section{TIKHOMIROVA \& LEBEDEVA}

technologies) and decrease of low-skilled economically active population increases the probability of a favorable immigration situation in the country. The level of well-being and the production orientation do not have a significant impact on the immigration attractiveness of the country. The logit model of emigration attractiveness, built on the principal components (see Equation 4) has the form:

$$
P\left(y_{i}=1 \mid x_{i}\right)=\frac{e^{0.8-0.4 F_{1}+0.7 F_{2}+0.6 F_{3}}}{1+e^{0.8-0.4 F_{1}+0.7 F_{2}+0.6 F_{3}}} И P\left(y_{i}=1 \mid x_{i}\right)=\frac{1}{1+e^{0.8-0.4 F_{1}+0.7 F_{2}+0.6 F_{3}}}
$$

The results of the calculation of the migration logit model for our binary data are shown in Table 5.

Table 5. Statistical characteristics of the quality of the logit model of emigration

\begin{tabular}{|c|c|c|c|c|c|c|c|}
\hline \multicolumn{3}{|c|}{ Logistic regression } & & \multicolumn{2}{|c|}{$\begin{array}{l}\text { Number of obs } \\
\text { LR chi2( } 3) \\
\text { Prob > chi2 } \\
\text { Pseudo R2 }\end{array}$} & $\begin{array}{l}= \\
= \\
= \\
=\end{array}$ & $\begin{array}{r}81 \\
20.00 \\
0.0002 \\
0.1915\end{array}$ \\
\hline$y$ & Coef. & Std. Err. & $z$ & $\mathrm{P}>|\mathrm{z}|$ & {$[95 \%$} & Conf. & Interva1] \\
\hline $\begin{array}{l}\operatorname{var} 1 \\
\operatorname{var} 2 \\
\operatorname{var} 3 \\
\text { cons }\end{array}$ & $\begin{array}{r}-.4161644 \\
.7433655 \\
.632219 \\
.8205362\end{array}$ & $\begin{array}{l}.1698982 \\
.2580387 \\
.2761407 \\
.2809636\end{array}$ & $\begin{array}{r}-2.45 \\
2.88 \\
2.29 \\
2.92\end{array}$ & $\begin{array}{l}0.014 \\
0.004 \\
0.022 \\
0.003\end{array}$ & $\begin{array}{r}-.7491 \\
.2376 \\
.0909 \\
.2698\end{array}$ & $\begin{array}{l}1588 \\
6189 \\
9931 \\
8577\end{array}$ & $\begin{array}{r}-.0831701 \\
1.249112 \\
1.173445 \\
1.371215\end{array}$ \\
\hline
\end{tabular}

Components $F_{1}, F_{2}, F_{3}$ and the constant have a significant impact on the amount of emigration. Econometric modeling of the attractiveness of emigration has revealed that with an increase in the production component of the economy and the labor shortage in the country, as well as a reduction of the development of the internal market, the probability of the country's emigration attractiveness grows.

\section{Conclusions}

From 15 variables that influence the number of immigrants in the EU, we identified four latent factors of immigration attractiveness: $F_{1}$ describes the technical equipment of the country; $F_{2}$ - the low level of skills of the economically active population; $F_{3}$ - level of production; $F_{4}$ - as a production oriented economy of the country. From 9 variables that influence the number of immigrants in the EU, we identified three latent factors of immigration 


\section{STATISTICAL MODELING OF MIGRATION ATTRACTIVENESS}

attractiveness: $F_{1}$ - underdevelopment of the domestic market of the country; $F_{2}-$ a scientific backwardness of the country; $F_{3}$ - the shortage of labor in the country.

Using an iterative approach of cluster analysis, discriminant analysis, and factor analysis we have received the stable classification of countries by the level of immigration and emigration. The countries were divided into two groups according to the immigration attractiveness. The first group included former capitalist countries (Belgium, Denmark, Germany, Ireland, Greece, Spain, France, Italy, Cyprus, Malta, the Netherlands, Austria, Portugal, Finland, Sweden, England, Norway) and the second included ex-socialist countries (Bulgaria, Czech Republic, Estonia, Latvia, Lithuania, Hungary, Poland, Romania, Slovenia, Slovakia, Croatia). This result has great importance, since during the study it was revealed that the EU, which has long sought to achieve economic and social equality, has not been able to overcome the historically formed significant differences in the levels of development. Luxembourg was not identified in any group, which confirms that Luxembourg has the economic status of a free economic zone.

According to the emigration attractiveness, EU countries were divided into three stable groups. The first group included Austria, Belgium, Great Britain, Hungary, Germany, Greece, Italy, Cyprus, Latvia, Netherlands, Norway, Poland, Portugal, Finland, France, Croatia, Sweden, Estonia, the second included Denmark, Ireland, Malta, and the third included Bulgaria, Spain, Romania, Slovakia, Slovenia, Czech Republic. Again Luxembourg was not identified in any group.

Econometric modeling of the immigration attractiveness allowed us to explain that increasing in technical equipment (development of IT technologies) and increasing skills of the economically active population increases the likelihood of a successful immigration situation in the country. Immigration situation does not change with the growth of the welfare of a country and the industrial economy orientation.

Econometric modeling of emigration attractiveness revealed that it is determined by an increase in the production component of the country's economy and labor shortages. With increasing underdevelopment of the domestic market the likelihood of a favorable emigration environment is decreased. The results of this study may be of practical interest for a variety of community and government organizations in making effective decisions in the field of migration policy by influencing the work of selected factors, as well as to predict the level of migration attractiveness in different countries. 


\section{TIKHOMIROVA \& LEBEDEVA}

\section{References}

Albertinelli, A., Knauth, B., Kraszewski, K., \& Thorogood, D. (Eds.). (2011). Migrants in Europe: A statistical portrait of the first and second generation (2011 Edition). Luxembourg: Publications Office of the European Union. doi:10.2785/5318

Institutul National de Statistica. (n.d.). Institutul National de Statistica. Retrieved from http://www.insse.ro/cms/

Migrants in Europe: A statistical portrait of the first and second generation, 2011 edition. (2012, March 19 - April 1). Demoscope Weekly, 503-504. Retrieved from http://demoscope.ru/weekly/2012/0503/biblio03.php.

Migration and migrant population statistics. (2015, May). In

Eurostat: Statistics Explained. Retrieved from http://ec.europa.eu/eurostat/statisticsexplained/index.php/Migration_and_migrant_population_statistics

National Statistics Office, Malta. (n.d.). NSO Online. Retrieved from http://nso.gov.mt/en/Pages/NSO-Home.aspx

Sartori, F. (2012). EU Member states granted citizenship to more than 800 000 persons in 2010. Statistics in focus, 45. http://ec.europa.eu/eurostat/documents/3433488/5585336/KS-SF-12-045EN.PDF/241b75f4-2dfb-4aca-b0ff-1b6c34a78dc8

Tikhomirov, N. P., Tikhomirova, T. M., Oushmaev O. S. (2011) Econometric methods and multivariate statistical analysis: A Textbook. Moscow: Economics. 